\title{
Design and Improvisation of Fire Fighting Bike
}

\author{
Hardik Zende, Akshay Singh Bais, Purushendra Singh Rathore, Sandeep Yadav, Rituraj Raghuvanshi
}

\begin{abstract}
The project titled Design and Improvisation of Fire Fighting Bike is associated with new technique installed on the present firefighting bike. Deals with the firefighting operations with a quick response time.As identical in urban areas the narrow and crowded spaces where the movement of fire engines are not possible the bike plays the upper hand role and work as a life saver.The purpose of firefighting bike is to help the fire fighter to beat the traffic congestion and reach out the place of emergency within time.With all the required firefighting equipment required to overcome a concentrated fire. The fire suppression needs to be done at the incipient stage where the heat and flame produced by the fire is at the minimum point. The expected outcome of the project will be, to counter the fire at its initial stage for better human safety and protection.
\end{abstract}

Keywords : Response Time, Traffic Congestion, Safety Standards, Extinguishers, Nozzle System, Navigation System, Rescue.

\section{INTRODUCTION}

Fire bike is a vehicle which is to be designed primarily for firefighting operations. A Fire Fighting Bike is a motorcycle used by a fire department. Several countries around the world use Fire Fighting Bikes, often to beat traffic congestion, and the equipment carried ranges from simple extinguishers to jet guns with hose rigs. Firefighters also use Fire Fighting Bikes to offer medical treatment.The primary purposes of a Fire bike include transporting fire fighters to an incident scene, providing water with which to fight a fire, and carrying other equipment's needed by fire fighters. specialized apparatus is used to provide hazardous materials mitigation and technical rescue.A typical modern Fire bike will carry tools for a wide range of firefighting tasks, with common equipment including extinguishers, a water tank, hoses, rescue box, hand tools, self-contained breathing apparatus (SCBA) and medical supplies.Many fire vehicles are based on standard vehicle models and they are normally fitted with audible and visual warnings, as well as communication equipment such as two-way radios and mobile computer technology.

\section{LITERATURE REVIEW}

Congested roads and mounting traffic on the city have considerably increased the response time of the fire brigade in reaching trouble spots across the city.

Revised Manuscript Received on March, 292020.

* Correspondence Author

Mr. Hardik Zende*, Scholar, Department of Fire Technology \& Safety Engineering, Medi-Caps University, Indore, India.

Mr. Akshay Singh Bais, Scholar, Department of Fire Technology \& Safety Engineering, Medi-Caps University, Indore, India.

Purushendra Singh, Scholar, Department of Fire Technology \& Safety Engineering, Medi-Caps University, Indore, India.

Sandeep Yadav, Assistant Professor, Department of Fire Technology \& Safety Engineering, Medi-Caps University, Indore, India.

Rituraj Raghuvanshi, Assistant Professor, Department of Fire Technology \& Safety Engineering Medi-Caps University, Indore, India.

(C) The Authors. Published by Blue Eyes Intelligence Engineering and Sciences Publication (BEIESP). This is an open access article under the CC BY-NC-ND license (http://creativecommons.org/licenses/by-nc-nd/4.0/)
Sunday's fire at a go down at Tonga stand, Tiwari, one of the congested areas in the city, has once again brought to fore the need for small fire tender. 'traffic delays the response time of the department by up to 20 minutes, a dangerous delay. The ideal response time should be five to ten minutes after the call is received. when congested area are affected, it become difficult, especially when the traffic situation is bad. Proshun Chakra borty.

\section{RESEARCH ANALYSIS}

Need of Fire Fighting BikeA fire can start anywhere, anytime and in just 6 minutes, it can turn into an uncontrolled blaze. This make it even more important for you to tackle the fire, before it is too late. Unfortunately, narrow lanes, inaccessible roads and traffic jams all are a setback when it comes to rushing to the rescue point. Which means that by the time the large fire engines reaches to the disaster point it could very possibly already be too late. "Fire Fighting Bike" comes to rescue in such situations. It can maneuver on any road, zip through traffic and reach the disaster site in a very short time.

Features-

Capable to overcome all classes of fire.

Quick control over fire at incipient stage.

Minimum man power as against 6 persons for a standard fire tender.

No external expellant require.

Optimal utilization of water and can be refilled from any water source.

GPS for short route and location.

Minimal operational cost.

Continuous Operation.

Economical and eco friendly.

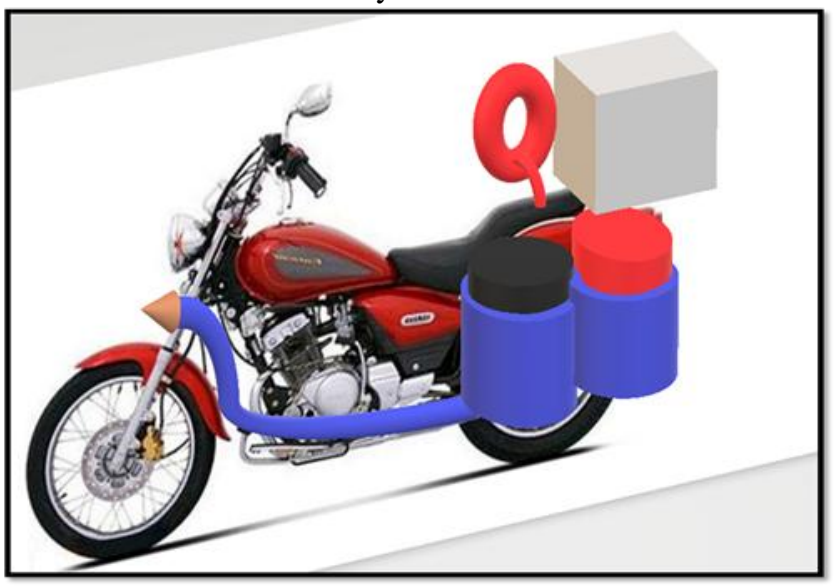

Figure1.1: Extinguisher Installation

\section{Engine}

Yamaha Enticer is a cruiser motorcycle, sold few years back in the entry level motorcycle segment in India. It is powered by a $200 \mathrm{cc}$, air cooled engine that produces $11 \mathrm{BHP}$ at 8000 rpm and 
$10.4 \mathrm{Nm}$ at $6500 \mathrm{rpm}$. It weighs just $115 \mathrm{~kg}$ and was preferred because of its peppy nature and easy riding dynamics. The top speed of the same is claimed to be 112 mph while its rivaled Bajaj Avenger in terms of design.

\section{Tool Box}

Tool box is a box which contains all the necessary items that are used or to be needed in case of emergency. Following are the list of items present in Tool box-

First Aid Kit

$15 \mathrm{~m}$ Hose

Fire Blanket

First Aid Kit (should be according to IS 13115)

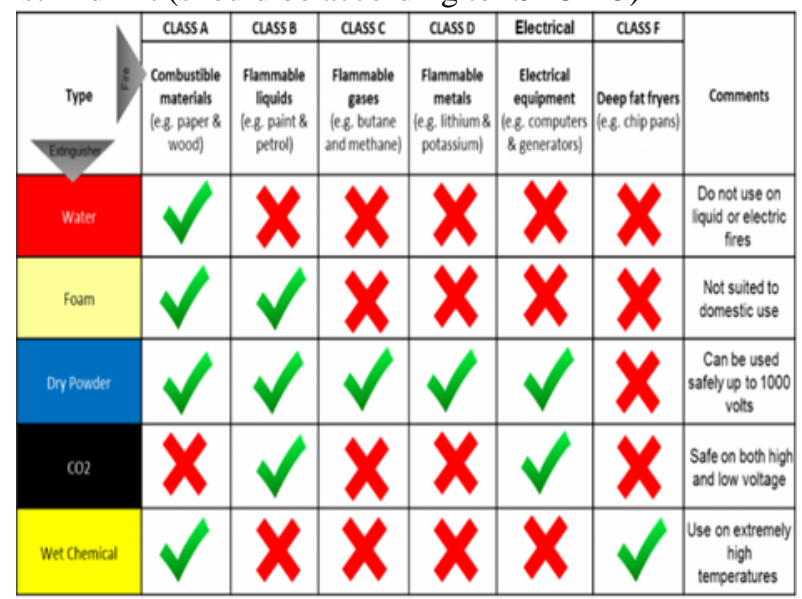

A first aid kit is a collection of supplies and equipment that is used to give medical treatment. There is a wide variation in the contents of first aid kits based on the knowledge and experience of those putting it together, the differing first aid requirements of the area where it may be used and variations in legislation or regulation in a given area.

\section{Fire Extinguisher}

A fire extinguisher is a equipment used to extinguish or control small fires and often used in emergency situations. Generally, a fire extinguisher has hand-held cylindrical pressure which is discharged to extinguish a fire.

\section{Front Nozzle System}

This system will be used to suppress the fire hurdles coming in front of the vehicle. This system can produce a jet of water up to 15 feet. This system comprises of a water storage tank, a piping system and a nozzle which are mounted on the leg guard. The water cylinder in the system can system as well as to extinguish the fire with the help of a hose This is basically a manually operated system which suppresses front fire automatically

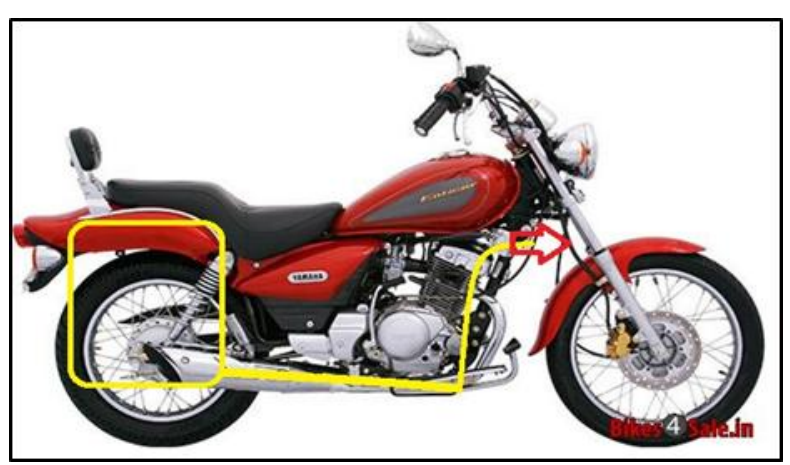

Figure1.2: Arrangement of Nozzle System

\section{Semi Fixed Hose Reel System}

This hose reel system is mounted just above the rescue box. The inlet valve is kept open for the application of outer pump. Length of reel will be around $8 \mathrm{~m}$. Water mist technology nozzle will be used.

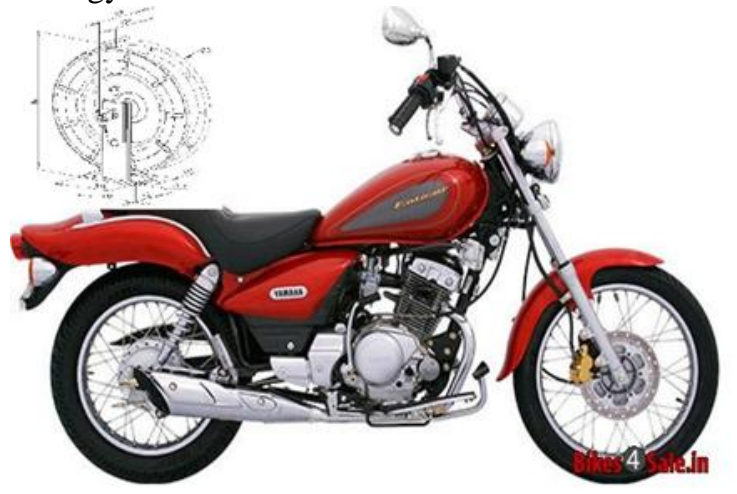

Figure1.3: Hose Reel Arrangement

\section{Navigation System}

It guides the shortest route to the destination. Software installed will provide data directly to the firefighter on his screen. It uses satellite information. Navigation system will be mounted on the just above the speedometer for a clear view of the guided destination. The navigation system can also be used for communication purposes in case of further requirements.

\section{RESULT}

The bike construction is done under the standard for all the equipment. The equipment installed on the bike are workable in all the situation of emergency.

The bike used is very powerful to bear all the capable load than been installed as to move including the weight of the firefighter.

Fire Hose Reels are easy to use as they are directly connected to the water supply having length up to $15 \mathrm{~m}$ and $30 \mathrm{~m}$.

\section{DCP Extinguisher}

The dry chemical powder extinguisher contains the high specification Purple K Powder for use in situations where high firefighting capability is required. This model is manufactured from high strength steel cylinders with a red epoxy polyester paint finish. Model 415 is supplied with a heavy-duty chrome plated brass valve and stainless-steel handles.

\begin{tabular}{|l|l|}
\hline Capacity & $9 \mathrm{~kg}$ \\
\hline Fire rating & $89 \mathrm{~B}$ \\
\hline Av. Charged Weight (kg) & 18 \\
\hline Operating Pres. (psi/bar) & $195 / 13.4$ \\
\hline Range (meters) & $5-7$ \\
\hline Av. Discharge Time (secs) & 16 \\
\hline Height (cm) & 61 \\
\hline Media & Purple K powder \\
\hline
\end{tabular}

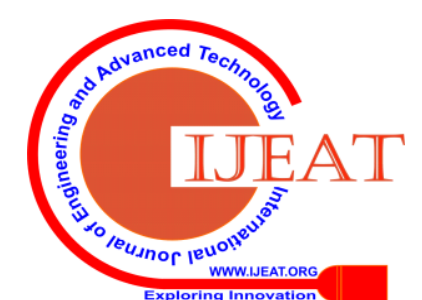


The bike contains a very good workmanship and finish the specification of the bike are as following.

\begin{tabular}{|l|l|}
\hline Engine & 150 cc \\
\hline Color & $\begin{array}{l}\text { Modified fire red (IS 5 } \\
\text { Shade 536) }\end{array}$ \\
\hline $\begin{array}{l}\text { Weight of passenger and } \\
\text { cargo }\end{array}$ & $150 \mathrm{~kg}$ (approx.) \\
\hline Fuel tank capacity & 10 litre \\
\hline
\end{tabular}

\section{Calculation}

\section{Load distribution}

Gross weight $=$ (kerb weight $)+$ (weight of passenger and cargo)

Kerb weight $=125 \mathrm{kgs}$

Weight of passenger and cargo $=150 \mathrm{kgs}$

Weight of passenger and cargo:

Passenger weight $=75 \mathrm{kgs}$

Extinguisher weight $=60 \mathrm{kgs}$

Tool box $=5 \mathrm{kgs}$

Other $=10 \mathrm{kgs}$

Total $=150 \mathrm{kgs}$

Gross weight $=125 \mathrm{kgs}+150 \mathrm{kgs}$

$$
=275 \mathrm{kgs}
$$

The gross vehicle weight will be around $275 \mathrm{kgs}$ which include all weight present of the fire bike.

\section{Fire extinguishing media}

DCP = 2 cylinder of 9 kgs (fire rating 89B)

Areacovered $=2 * 89$ square feet (according to fire rating 21B)

$$
=178 \text { square feet }
$$

The area covered by the DCP cylinder is around 42 square feet according to the fire rating of the extinguisher.

Fire rating $89 \mathrm{~B}$ means it is suitable to extinguish the fire of class $\mathrm{B}$ with the area covered are denoted by the numerical prefix denoting the area covered in square feet.

Water $=2$ cylinder of 9liters (fire rating 21A)

Area covered $=2 * 21$ square feet (according to fire rating 21A)

$$
=42 \text { square feet }
$$

The area covered by the water cylinder will be around 42 square feet according to fire rating of the extinguisher.

The rating 21 A denote suitable for A class of fire and 21 denote the water equivalency rating $1 \mathrm{~A}$ is equivalent to 1.25 gallons of water.

\section{CONCLUSION}

Overall, the design and improvisation of Fire Fighting bike has been successfully done. All the action which has to be performed like fighting with fire in running vehicle condition, semi fixed Hose reel system, Navigation System and Extinguisher is working properly. Firefighting bike with these modifications will be a new success in terms of safety as well as firefighting and rescue operations. The problem for which the solution in the form of this project is given was to develop a small, portable and light multipurpose firefighting equipment which provides aid in rescue services in small duration of time and even in the busiest of the city traffic to minimize, reduce and eliminate hazards that occur due to fire in places which are in confined areas and are also not accessible by larger and bulkier full sized fire tender. We by working on this project are trying to improve and develop solutions for such situations and emergencies.

It is will also set a future mark for the safety vehicle manufacturer as it will be capable to extinguish fire in running vehicle condition. As, a conclusion the project entitled 'The design and improvisation of firefighting bike' has achieved its aim and objectives successfully.

\section{REFERENCES}

1. Accident Prevention Manual for Industrial Operations,

National Safety Council, Chicago, Illinois.

2. NFPA Fire Protection Manual (16 volumes), USA.

3. Fire Protection Manual, Factory Manual Systems, HMSO, London.

4. Fire Protection Guide on Hazardous Materials, National Fire Protection, USA

5. A handbook of Fire Technology, R.S. Gupta, Orient Longman Ltd., Mumbai.

6. Dust Explosions and Fires, K.N. Palmer, Chapman and Hall, London.

7. Fuel and Combustion, Sharma, Tata McGraw Hill, Delhi.

8. Smoke Control in Fire Safety Design, Butcher and Parnell, E \& FN Spon Ltd., London.

9. Rules for Segregation, Tariff Advisory Committee, Bombay Regional Committee, Bombay.

10. Loss Prevention in the Process Industries, Frank P. Lees, Butterworth.

11. Major Hazard Control, a practical manual, ILO, Geneva.

12. The Factories Act \& Rules.

13. Industrial Fire Protection Handbook. R.Craig Schroll

\section{AUTHORS PROFILE}

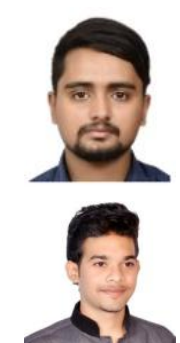

Mr. Hardik Zende (B.Tech Scholar) Fire Technology \& Safety Engineering Medi - Caps University, Indore, India

Mr. Akshay Singh Bais (B.Tech Scholar) Fire Technology \& Safety Engineering Medi - Caps University, Indore, India

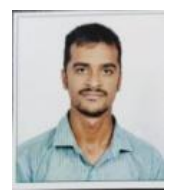

Purushendra Singh (B.Tech Scholar) Fire Technology \& Safety Engineering Medi - Caps University, Indore, India

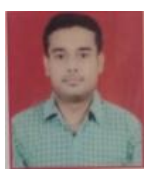

Sandeep Yadav (Ph.D). (Mechanical Engineering), Assistant Professor, Department of Fire Technology \& Safety Engineering Medi-Caps University, Indore, India

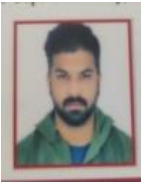

Rituraj Raghuvanshi (M.Tech) (Industrial Safety Engineering), Assistant Professor, Department of Fire Technology \& Safety Engineering Medi-Caps University, Indore, India 